\title{
Opinions towards skin ageing in the elderly inhabitants of Bialystok, Poland
}

Mateusz Cybulski, Elzbieta Krajewska-Kulak

Skin diseases constitute an essential health and aesthetic problem in the group of the elderly. The aim of the study was to evaluate the knowledge of the elderly residents of public nursing homes and participants of the University of the Third Age in Bialystok, Poland surrounding the factors influencing skin ageing; the awareness of skin conditions in aged skin; and the impact of skin ageing on the volunteers. The study was performed from April to June 2015, in Bialystok, in two groups: among 100 public nursing home residents (PNH) and 100 members of University of the Third Age (U3A), (all over 60 years old). The study made use of a diagnostic survey conducted via a questionnaire prepared by the authors. Nearly half of those surveyed $(42.5 \% ; n=85)$ sunbathed in the past, while $28.0 \%$ $(n=56)$ of those surveyed now take part in this type of leisure activity. More than half of respondents (53.0\%; $n=106)$ protected their skin using special protective preparations. A majority of Bialystok inhabitants surveyed $(80.5 \% ; n=161)$ noticed features of skin ageing. They reported birthmarks, fungal infections and bedsores as main skin problems of the old age. Nearly half $-40.0 \%$ of respondents assessed their knowledge as average and $26.0 \%$ as poor. The study showed some statistical differences in the knowledge and awareness between the residents of public nursing homes and the students of the University of the Third Age, e.g. the use of the Internet by the U3A group for finding out information. There is a desire to receive education in the field of the old age skin conditions/diseases among the elderly, because their level of knowledge is relatively poor. Education of seniors in this area can increase their awareness of the basic principles of skin care and prevention marking of skin ageing. The benefits of greater knowledge of seniors about ageing skin condition can help reduce the medical burden and reduce incidence on certain skin diseases. Furthermore, there is a need for education of the younger population on the factors of skin ageing to prevent certain skin conditions in the older age. Seniors should be educated professionally by qualified specialists, for example dermatologists, cosmeticians. The information the elderly obtain should be established in accordance with evidence based medicine, not on colourful magazines for women. 
1 Opinions towards skin ageing in the elderly inhabitants of Bialystok, Poland

2

3 Mateusz Cybulski ${ }^{1}$, Elzbieta Krajewska-Kulak ${ }^{1}$

$4{ }^{1}$ - Department of Integrated Medical Care, Medical University of Bialystok, Poland

5

6 Corresponding author:

7 Mateusz Cybulski ${ }^{1}, \mathrm{PhD}$

8 7A Sklodowskiej-Curie Str., 15-096 Bialystok, Poland

9 e-mail: mateusz.cybulski@umb.edu.pl

10

11

12

13

14

15

16

17

18

19

20

21

22

23

24

25

26

27

28 
ABSTRACT

\section{Background}

Skin diseases constitute an essential health and aesthetic problem in the group of the elderly. The aim of the study was to evaluate the knowledge of the elderly residents of public nursing homes and participants of the University of the Third Age in Bialystok, Poland surrounding the factors influencing skin ageing; the awareness of skin conditions in aged skin; and the impact of skin ageing on the volunteers.

\section{Methods}

The study was performed from April to June 2015, in Bialystok, in two groups: among 100 public nursing home residents (PNH) and 100 members of University of the Third Age (U3A), (all over 60 years old). The study made use of a diagnostic survey conducted via a questionnaire prepared by the authors.

\section{Results}

Nearly half of those surveyed $(42.5 \% ; n=85)$ sunbathed in the past, while $28.0 \%(n=56)$ of those surveyed now take part in this type of leisure activity. More than half of respondents $(53.0 \%$; $\mathrm{n}=106$ ) protected their skin using special protective preparations. A majority of Bialystok inhabitants surveyed $(80.5 \% ; n=161)$ noticed features of skin ageing. They reported birthmarks, fungal infections and bedsores as main skin problems of the old age. Nearly half $-40.0 \%$ of respondents assessed their knowledge as average and $26.0 \%$ as poor.

\section{Conclusions}

The study showed no significant differences in knowledge and awareness between the residents of public nursing homes and students of the University of the Third Age. There is a need for education of seniors about skin, because their level of knowledge is relatively poor. Furthermore, there is a need for education of the younger population on the factors of skin ageing to prevent certain skin conditions as people get older.

Key words: ageing, elderly, factors, older people, photoageing, skin ageing

\section{INTRODUCTION}


60

61

62

63

64

65

66

67

In the biological sense, ageing of an organism is a process defined as a syndrome of progressive

changes over time, including, among others:

- decreased biological activity of cells;

- decreased regenerative processes;

- decreased immunity and response to an environmental stress;

- decreased genetic - dependent adaptation properties of an organism (Zegarska \& Wozniak, 2006).

According to assumptions of the demographic projections, performed by the Central Statistical Office of Poland (2014) up to the year 2050, a significant decrease in the population of children and adults and an increase in the number of the elderly is expected. According to the assumptions above, by 2050 , people at least 80 years old will constitute $10.4 \%$ of the country's population, compared to $3.9 \%$ in 2013 . Among 3.5 million of the Polish population aged 80 and older, in the year 2013, more than 59 thousand will have lived to be 100 years old by 2050. In Poland, the longest living inhabitants (especially women) are in the Podlasie province with its capital - Bialystok (Central Statistical Office of Poland, 2014).

The skin, similarly to all other body parts and tissues, is subjected to ageing due to intrinsic and extrinsic factors. Many analogies between ageing in skin and other organs can be found (Kane, Ouslander \& Abrass, 1998). Wrinkles appearing on the face are one of the first signs of ageing (Rexbye et al., 2006).

Skin diseases constitute an essential health and aesthetic problem in the elderly. Many of these diseases are caused by long-term exposure to stressful situations and impaired quality of the elderly person's life, including those caused by chronic diseases and smoking (Daniell, 1971; Model, 1985; Kadunce et al., 1991; Ernster et al., 1995), or overexposure to natural (Leyden, 1990; Yaar, Eller \& Gilchrest, 2002), or artificial ultraviolet radiation (Jayaprakasam et al., 2002; Shah $\&$ Coates, 2006).

At present, smoking belongs to one of the two most serious extrinsic factors, causing the most significant lesions in the skin (Kennedy et al., 2003), with the other, the skin exposure to UV radiation (Farage et al., 2008). It has been proven in the literature (Leow \& Maibach, 1998) that smoking is a predictor of telangiectasia. Additionally, smoking cigarettes damages the skin by a decrease in capillary blood flow in the skin, which results in a decrease in the volume of oxygen 
91 and nutrients in the dermal tissues. Other studies have shown that smokers have fewer fibres of 92 collagen and elastin, which makes the skin loose and less elastic, facilitating wrinkles (Leow \& Maibach, 1998). Rexbye et al. (2006) also proved that smoking was markedly associated with an increase in perceiving the age in men. It was established that smoking 20 cigarettes daily equalled an additional year in perceived age. In case of women, an additional year of skin ageing corresponded to smoking 20 cigarettes daily for 40 years (Rexbye et al., 2006). According to Seddon et al. (1992), smoking 30 cigarettes daily at the age of 70 equalled about 14 years of skin ageing.

The aim of the study was to evaluate the knowledge of the elderly residents of public nursing homes and participants of the University of the Third Age in Bialystok, Poland surrounding the factors influencing skin ageing; the awareness of skin conditions in aged skin; and the impact of skin ageing on the volunteers. In reference to the aims of the study we formulated the following hypothesis to test via questionnaire based study „knowledge and awareness of skin ageing is variable between elderly populations with different socioeconomic status".

\section{MATERIALS \& METHODS}

\section{Participants}

The research was conducted in two groups - among 100 residents of Public Nursing Home (PNH) in 9 Swierkowa St. in Bialystok and among 100 participants of University of the Third Age (U3A) in Bialystok. A total of 200 people over 60 years old were included in the study.

The criteria of inclusion were defined as follows: age $>60$ years, respondents had to be inhabitants of Bialystok or the surrounding area, refer to the subject of the study and give written consent to participate in the study. An additional criterion of inclusion involving students of the U3A was the participation in lectures, because the study was conducted immediately before lectures. The criterion of exclusion was the incidence of dementia in the older person. Given the inclusion and exclusion criteria of the study, the research team sought to create a representative sample of the study groups. Therefore, it was decided to form two groups consisting of 100 respondents. The selection of groups was intentional and the choice of subjects in groups had a random character including the above criteria. 
The authors decided to compare the results of research in the group of residents of PNH

121

122

123

124

125

126

127

128

129

130

131

132

133

134

135

136

137

138

139

140

141

142

143

144

145

146

147

148

149

150

and participants of U3A, because it was assumed that there might be significant differences in the results due to socio-economic status between representatives of both groups.

\section{Measurements and procedure}

The study made use of a diagnostic survey conducted via a questionnaire prepared by the authors. It consisted of 35 questions, both open and closed, one or multiple choice. The questions concerned social-demographic characteristics (sex, marital status, place of living, education, financial status), respondents' knowledge of and use of basic preventative measures to avoid skin diseases (frequency of sunbathing and exposure to artificial UV light in solarium, protection of the skin against outer agents, applied cosmetics for skin care), knowledge of major skin problems in seniors (knowledge about factors affecting skin ageing, stigma of the senior age skin, the commonest skin problems among the elderly) and subjective assessment of the knowledge and its sources.

\section{Procedure and ethical considerations}

The study was performed from April to June 2015. The research conforms with the Good Clinical Practice guidelines and the procedures followed were in accordance with the Helsinki Declaration of 1975, as revised in 2000 (concerning the ethical principles for the medical community and forbidding releasing the name of the patient, initials or the hospital evidence number) and with the ethical standards of the institutional committee on human experimentation (statute from the Bioethics Committee of the Medical University in Bialystok no. R-I002/417/2014). All respondents gave written consent to fill out an anonymous questionnaire.

\section{Statistical analysis}

All data obtained during the study were compiled using Microsoft Excel 2010. Statistical analysis was completed by applying the Chi-squared test. Using the chi-square test, we compared qualitative variables (groups) with quantitative variables (the type of cosmetics used, sources of information about dermatological diseases, etc.). The study meets all the conditions for the application of chi-square test, especially the minimum sample size and the independence of groups. Statistical hypotheses were verified at the $\mathrm{P} \leq 0.05$ significance level, which means that it accepts the one error of the first kind in the 20 analyses. A confidence interval (CI) was calculated for each parameter using an $\alpha=5 \%$. Calculations were completed using STATISTICA Data Miner + QC PL program. 


\section{RESULTS}

153

154

155

156

157

158

159

160

161

162

163

164

165

166

167

168

169

170

171

172

173

174

175

176

177

178

179

180

\section{Baseline characteristics of the study population}

In our study, women constituted $68.0 \%(n=136)$, men - 32.0\% $(n=64)$. Among residents of $\mathrm{PNH}$, there were 59 women and 41 men, while in members of U3A - 77 women and 23 men. People over 70 years old predominated $(62.5 \%$; $n=125)$, people aged from 61 to 70 years old $(n=75)$ constituted $37.5 \%$. More than $40.0 \%$ of the surveyed $(42.5 \% ; n=85)$ were widows/widowers, $30.0 \%$ were married, $15.0 \%$ - were singles and $12.0 \%$ - divorced. A significant majority of the respondents lived in the city - Bialystok $(91.5 \%, n=183)$, whereas only 5.5\% $(n=11)$ in the rural area. A total of $45.0 \%$ of the surveyed $(n=90)$ defined their financial status as average, and 39.5\% $(\mathrm{n}=79)$ as good. Among PNH residents, 54.0\% described their financial status as average, while $58.0 \%$ of U3A members considered as good. People with higher education $(50.0 \%)$ and secondary education $(44.0 \%)$ predominated in this group. Residents of PNH varied more with regard to the education level $-27.0 \%$ had vocational education, $26.0 \%$ - secondary education , $20.0 \%$ - primary education, $15.0 \%$ - higher education and $12.0 \%$ - technical education.

\section{Type of the skin and skin-associated problems of study participants}

Almost $1 / 3$ of the total questioned $(33.0 \% ; n=66)$ had a mixed type of the skin - in the PNH residents, this percentage equalled $35.0 \%$, whereas in U3A members $-31.0 \%$. A slightly smaller percentage of people $(25.5 \%, 51$ people) had dry skin. An insignificant percentage of people had other types of skin. Nobody had acne skin. A total of 21 people $(10.5 \%)$ did not know the type of their skin.

More than $60.0 \%$ of all respondents $(62.5 \% ; n=125)$, including $54.0 \%$ of PNH residents and $76.0 \%$ of U3A participants had no skin-associated problems in the past, whereas $28.5 \%$ of the respondents $(n=57)$ answered positively and 9.0\% $(n=18)$ answered 'I don't know'.

\section{The frequency of sunbathing of the respondents}

Almost half of the respondents from Bialystok $(42.5 \% ; n=85)$ sunbathed in the past, but at present, they have stopped doing this. A total of $28.0 \%(n=56)$ nowe take part in this leisure activity, whereas $29.5 \%$ had never improved the skin complexion in this way. Answers concerning indoor tanning were completely different. As many as $93.0 \%$ of the respondents $(n=186)$ had never used this type of services, $6.0 \%(n=12)$ tanned indoors in the past, and only $1.0 \%(\mathrm{n}=2)$ at present. 
181 It should be highlighted that of 14 people who had ever tanned indoors, 13 were the members of 182 U3A.

183 Use of special protective preparations by the respondents

184 Additionally, more than half of the respondents $(53.0 \%$; $n=106)$ protected the skin with 185 special protective preparations. A quite high percentage of people $(38.5 \% ; n=77)$ used no such 186 preparations. Creams $(86.5 \% ; \mathrm{n}=173, P=0.063)$ were most frequently used. Fig. 1 shows the 187 detailed data.

188 [Figure 1 is here]

189 Figure 1. Cosmetics for skin care used by respondents. * Statistically significant difference $190(P<0.05)$, PNH - Public Nursing Home, U3A - University of the Third Age.

191 The features of skin ageing of the study population

192

193

194

195

196

197

198

199

200

201

202

203

204

205

206

207

208

209

210

A majority of the respondents from Bialystok $(81.5 \% ; n=161)$ showed signs of ageing skin. Only $9.5 \%$ of the questioned observed no changes, and $10.0 \%$ - were not able to state whether these changes occurred. General health conditions, smoking and stress were pointed to as factors influencing skin ageing (Fig. 2).

[Figure 2 is here]

Figure 2. Factors influencing skin ageing in the opinion of respondents. * Statistically significant difference $(P<0.05)$, PNH - Public Nursing Home, U3A - University of the Third Age.

\section{Signs of ageing in the skin in the respondent's opinion}

The most frequent signs of ageing in skin that were reported in the study are shown in Fig. 3. In the study, respondents most frequently pointed to wrinkles $(80.5 \%)$, skin slackening $(56.0 \%)$ and greying of hair $(50.5 \%)$.

[Figure 3 is here]

Figure 3. Typical stigma of ageing skin in the opinion of respondents. * Statistically significant difference $(\mathrm{P}<0.05)$, PNH - Public Nursing Home, U3A - University of the Third Age.

\section{Skin problems of the elderly}

Respondents considered birthmarks, fungal infections and bedsores as main skin problems of the elderly. Detailed data, including the division into PNH residents and U3A participants and the value $P$ were presented in Fig. 4.

[Figure 4 is here] 
211 Figure 4. The most frequent skin problems in the elderly in the opinion of respondents. *

212 Statistically significant difference $(\mathrm{P}<0.05), \mathrm{PNH}-$ Public Nursing Home, U3A - University of 213 the Third Age.

\section{Level of the knowledge on dermatological diseases}

Those questioned did not have a high level of knowledge about dermatological diseases.

More than $40.0 \%$ of all respondents $(36.0 \%$ of PNH residents and $46.0 \%$ of U3A participants)

217

218

219

220

221

222

223

224

225

226

227

228

229

230

231

232

233

234

235

236

237

238

239

240

241 assessed their knowledge as average and 26.0\% (35.0\% of PNH residents and $17.0 \%$ of U3A participants) as poor. One person from U3A had very good knowledge and 24 people (12.0\%) good. U3A members also predominated in this case $(16.0 \%$ of U3A members vs. $8.0 \%$ of PNH residents). The main sources of information about skin diseases of the elderly were newspapers and a physician (each $44.0 \% ; n=88$ ). Reading newspapers was the most popular among U3A participants $(50.0 \%)$, while the information obtained from a physician - among PNH residents (55.0\%). Other sources were shown in Fig. 5.

\section{[Figure 5 is here]}

Figure 5. Respondents' sources of information about skin diseases in seniors. * Statistically significant difference $(\mathrm{P}<0.05)$, PNH - Public Nursing Home, U3A - University of the Third Age.

\section{The need for education about skin diseases among the elderly}

A total of $60.5 \%(n=121)$ of respondents answered 'Yes' to the question 'Would you like to be educated with regard to skin diseases of the elderly?', while $8.5 \%(n=17)$ answered 'No' and $31.0 \%(n=62)$ had a problem to declare and chose the answer : 'It is difficult to say'. Analysis of 181 the group distribution of answers to the question revealed that $49.0 \%$ of PNH residents and as many as $72.0 \%$ of U3A members answered 'Yes', whereas $10.0 \%$ of PNH residents and $7.0 \%$ of U3A participants answered 'No'. Finally, $41.0 \%$ of PNH residents and $21.0 \%$ of U3A students answered 'I do not know'.

\section{DISCUSSION}

Stasis dermatitis is one of the most frequent skin diseases in the seniors. This diseases is a cutaneous manifestation and marker of increased venous pessure of the lower extremities. It is a common condition affecting predominantly middle-aged to elderly individuals that usually presents as erythematous, slightly yellow to brown pigmented patches over the bilateral lower legs 
242 with or without conspicuous varicose veins. Most cases are caused by insufficient deep venous

243 system valves preventing proper return of blood to the central circulation through the muscular 244 pumping action of the lower legs. Venous valvular insufficiency can be caused by prior 245 thrombophlebitis or congenital fragility. Obesity, and other causes of increased abdominal pressure 246 can also lead to chronic venous insufficiency (Weaver \& Billings, 2009). When left untreated or 247 treated inadequately lesions may lead to ulceration of lower legs (Thaipisuttikul, 1998; Baeke, 248 2000). Lower legs ulceration was the most common cause of hospitalization among patients 249 examined by Pawlaczyk \& Zukowska (2011). The second cause of hospitalization was eczema 250 and next (more than 10\%) - psoriasis (Pawlaczyk \& Zukowska, 2011). Similarly, in the study of 251 Thapa et al. (2012), eczema (35.8\%) was the most frequent form of dermatosis. Among geriatric 252 patients of Taiwan, dermatitis, fungal skin infection and pruritic dermatosa were the most common 253 skin problems (Liao, 2001). In Singapore, in patients over 75 years old, eczema, dermatitis and 254 epidermic keratoses were the most frequent skin diseases (Yap, Siew \& Goh, 1994). In the 255 population of Germans, contact eczema, acne, and seborrheic dermatitis were reported most 256 frequently (Schaefer et al., 2008). In our study, respondents mentioned the most frequently 257 birthmarks, fungal skin infections and decubitus ulcers as the most common skin problems of seniors. The respondents or members of their families might have had these types of skin problems. U3A students as the most common sign of ageing pointed the fragile nails. This could be caused by exposure to moisture (e.g. washing the dishes), greater than among of PNH inhabitants. Besides, among the U3A participants was more women than among PNH residents. The available research suggests that the fragility of the nails women than men are more vulnerable. Age spots occur relatively frequently among U3A students than PNH residents. This could be due to greater exposure of U3A respondents to sunlight and ultraviolet radiation.

Bedsores and leg ulcers are a greater problem for the PNH. This could be due to a relatively were also statistically more frequently indicated in this group of respodents.

The skin condition depends on the environmental conditions, like temperature and humidity. McCallion \& Li Wan Po (1993) report that an increase in temperature by $7-8{ }^{\circ} \mathrm{C}$ doubles the loss of water evaporation, whereas the low temperature increases skin rigidity and decreases water loss by evaporation. In regard to the above information, the results of our study indicated 
272 that $53.0 \%$ of inhabitants of Bialystok questioned in the study protected the skin using special

273 protective preparations, against harmful atmospheric conditions, like frost or wind.

274

275

276

277

278

279

280

281

282

283

284

285

286

287

288

289

290

291

292

293

294

295

296

297

298

299

300

301

302

In his study, Rexbye et al. (2006) proved that tobacco smoking was significantly associated with visual ageing. The same opinion about smoking cigarettes was expressed by the respondents in our study - they also considered tobacco smoking as the main factor determining skin ageing.

Solar radiation is responsible for $90 \%$ of visual skin ageing (Martini, 2004; Sudel et al., 2005). Solar radiation consists of three different types of radiation: UVC, UVB and UVA. UVC is to a great extent blocked by an ozone layer and has a little influence on the skin (Gilchrest, 1996). UVB transfers exclusively to epidermis and is responsible for erythema (rash, redness) associated with sun burn (Gilchrest, 1996). UVA is characterised by a 1000-fold higher radiation, causing sun burn at the same time. Additionally, it penetrates to dermis and is responsible for a majority of skin lesions, causing photoageing (Gilchrest, 1996). Moreover, radiation UV has been proven to have cancerogenic effects, as well (Martini, 2004). In our study, nearly $3 / 4$ of respondents have sunbathed at least once at their own choice and they sunbathed more frequently in the pastthan at present. It is reassuring that $93.0 \%$ of the surveyed had never tanned indoors, which has even more harmful effect on the human health state than natural solar radiation.

\section{CONCLUSIONS}

1. The study showed some statistical differences in the knowledge and awareness between the residents of public nursing homes and the students of the University of the Third Age, e.g. the use of the Internet by the U3A group for finding out information

2. There is a desire to receive education in the field of the old age skin conditions/diseases among the elderly, because their level of knowledge is relatively poor. Education of seniors in this area can increase their awareness of the basic principles of skin care and prevention marking of skin ageing. The benefits of greater knowledge of seniors about ageing skin condition can help reduce the medical burden and reduce incidence on certain skin diseases. Furthermore, there is a need for education of the younger population on the factors of skin ageing to prevent certain skin conditions in the older age.

3. Seniors should be educated professionally by qualified specialists, for example dermatologists, cosmeticians. The information the elderly obtain should be established in accordance with evidence - based medicine, not on colourful magazines for women. 
304

305

306

307

308

309

310

311

312

313

314

315

316

317

318

319

320

321

322

323

324

325

326

327

328

329

330

331

332

333

\section{REFERENCES}

1. Baeke JL. 2000. Hospital-acquired pressure ulcers: an epidemic. Plastic and Reconstructive Surgery 106: 945-946. DOI: 10.1097/00006534-200009020-00043.

2. Central Statistical Office of Poland. 2014. The demographic situation of the elderly and implications of aging of the Polish population in the light of the forecasts for the years 2014-2050.

Available

at http://stat.gov.pl/download/gfx/portalinformacyjny/pl/defaultaktualnosci/5468/18/1/1/lud nosc_w_starszym_wieku.pdf. (accessed 9th December 2015)

3. Daniell HW. 1971. Smoker's wrinkles. A study in the epidemiology of "crow's feet". Annals of Internal Medicine 75: 873-880. DOI: 10.7326/0003-4819-75-6-873.

4. Ernster VL, Grady D, Miike R, Black D, Selby J, Kerlikowske K. 1995. Facial wrinkling in men and women, by smoking status. American Journal of Public Health 85: 78-82. DOI: 10.2105/ajph.85.1.78.

5. Farage MA, Miller KW, Elsner P, Maibach HI. 2008. Intrinsic and extrinsic factors in skin aging: a review. International Journal of Cosmetic Science 30: 87-95. DOI: 259 10.1111/j.1468-2494.2007.00415.x.

6. Gilchrest BA. 1996. A review of skin aging and its medical therapy. British Journal of Dermatology 135: 867-875. DOI: 10.1046/j.1365-2133.1996.d01-1088.x.

7. Jayaprakasam A, Darvay A, Osborne G, McGibbon D. 2002. Comparison of severity and quality of life in cutaneous disease. Clinical and Experimental Dermatology 27: 306-308. DOI: 10.1046/j.1365-2230.2002.01025.x.

8. Kadunce DP, Burr R, Gress R, Kanner R, Lyon JL, Zone JJ. 1991. Cigarette smoking: risk factor for premature facial wrinkling. Annals of Internal Medicine 114: 840-844. DOI: 267 10.7326/0003-4819-114-10-840.

9. Kane RL, Ouslander JG, Abrass IB. 1998. Clinical associations of the aging process. In: Kane RL, Ouslander JG, Abrass IB, eds. Essentials of clinical geriatrics. New York: McGraw-Hill, 3-18.

10. Kennedy C, Bastiaens MT, Bajdik CD, Willemze R, Westendorp RG, Bouwes Bavinck N. 2003. Effect of smoking and sun on the aging skin. Journal of Investigative Dermatology 120: 548-554. DOI: 10.1046/j.1523-1747.2003.12092.x. 
334

335

336

337

338

339

340

341

342

343

344

345

346

11. Leow YH, Maibach HI. 1998. Cigarette smoking, cutaneous vasculature, and tissue oxygen. Clinics in Dermatology 16: 579-584. DOI: 10.1016/s0738-081x(98)00042-x.

12. Leyden JJ. 1990. Clinical features of aging skin. British Journal of Dermatology 122: 1-3. DOI: 10.1111/j.1365-2133.1990.tb16118.x.

13. Liao YH, Chen KH, Tseng MP, Sun CC. 2001. Pattern of Skin Diseases in a Geriatric Patient Group in Taiwan: A 7-Year Survey from the Outpatient Clinic of a University Medical Center. Dermatology 203: 308-313. DOI: 10.1159/000051778.

14. Martini F. 2004. Fundamentals of Anatomy and Physiology. San Francisco: BenjaminCummings.

15. McCallion R, Li Wan Po A. 1993. Dry and photo-aged skin: manifestations and management. Journal of Clinical Pharmacy and Therapeutics 18: 15-32. DOI: 10.1111/j.1365-2710.1993.tb00562.x.

16. Model D. 1985. Smoker's face: an underrated clinical sign? British Medical Journal 291: 1760-1762. DOI: 10.1136/bmj.291.6511.1760.

17. Pawlaczyk M, Zukowska E. 2011. Analysis of dermatoses treated at the dermatological ward in elderly patients. Geriatria 5: 94-98.

18. Rexbye H, Petersen I, Johansens M, Klitkou L, Jeune B, Christensen K. 2006. Influence of environmental factors on facial aging. Age and Ageing 35: 110-115. DOI: 10.1093/ageing/afj031.

19. Schaefer I, Rustenbach SJ, Zimmer L, Augustin M. 2008. Prevalence of Skin Diseases in a Cohort of 48,665 Employees in Germany. Dermatology 217: 169-172. DOI: $10.1159 / 000136656$.

20. Seddon JM, Egan KM, Zhang Y, Gelles EJ, Glynn RJ, Tucker CA, Gragoudas ES. 1992. Evaluation of skin microtopography as a measure of ultraviolet exposure. Investigative Ophthalmology \& Visual Sciance 33: 1903-1908.

21. Shah M, Coates M. 2006. An assessment of the quality of life in older patients with skin disease. British Journal of Dermatology 154: 150-153. DOI: 10.1111/j.1365-301 2133.2005.06959.x.

22. Sudel KM, Venzke K, Mielke H, Breitenbach U, Mundt C, Jaspers S, Koop U, Sauermann K, Knussman-Hartig E, Moll I, Gercken G, Young AR, Stäb F, Wenck H, Gallinat S. 2005. Novel aspects of intrinsic and extrinsic aging of human skin: beneficial effects of soy 
365

366

367

368

369

370

371

372

373

374

375

376

377

378

379

extract. Photochemistry and Photobiology 81: 581-587. DOI: 10.1562/2004-06-16-ra202.1.

23. Thaipisuttikul Y. 1998. Pruritic skin diseases in the elderly. The Journal of Dermatology 25: 153-157. DOI: 10.1111/j.1346-8138.1998.tb02371.x.

24. Thapa DP, Jha AK, Kharel C, Shrestha S. 2012. Dermatological problems in geriatric patients: a hospital based study. Nepal Medical College Journal 14: 193-195.

25. Weaver J, Billings SD. 2009. Initial presentation of stasis dermatitis mimicking solitary lesions: A previously unrecognized clinical scenario. Journal of the American Academy of Dermatology 61: 1028-1032. DOI: 10.1016/j.jaad.2009.04.025.

26. Yaar M, Eller MS, Gilchrest BA. 2002. Fifty years of skin aging. Journal of Investigative Dermatology Symposium Proceedings 7: 51-58. DOI: 10.1046/j.1523-1747.2002.19636.x. 27. Yap KB, Siew MG, Goh CL. 1994. Pattern of skin diseases in the elderly seen at the National Skin Centre (Singapore) 1990. Singapore Medical Journal 35: 147-150.

28. Zegarska B, Wozniak M. 2006. Reasons of endogenous aging of the skin. Gerontologia Polska 14: 153-159. 


\section{1}

Cosmetics for skin care used by respondents

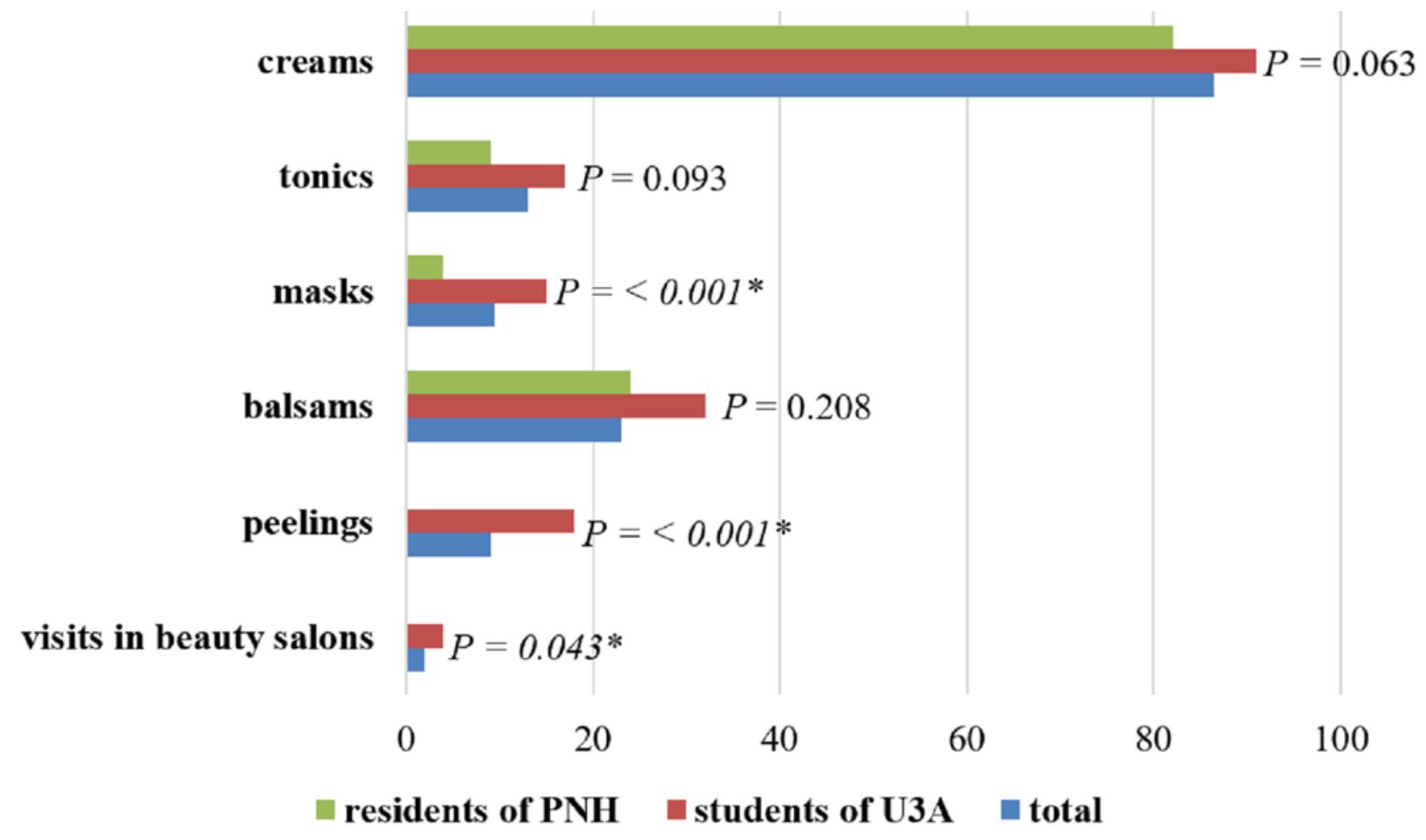


2

Factors influencing skin ageing in the opinion of respondents

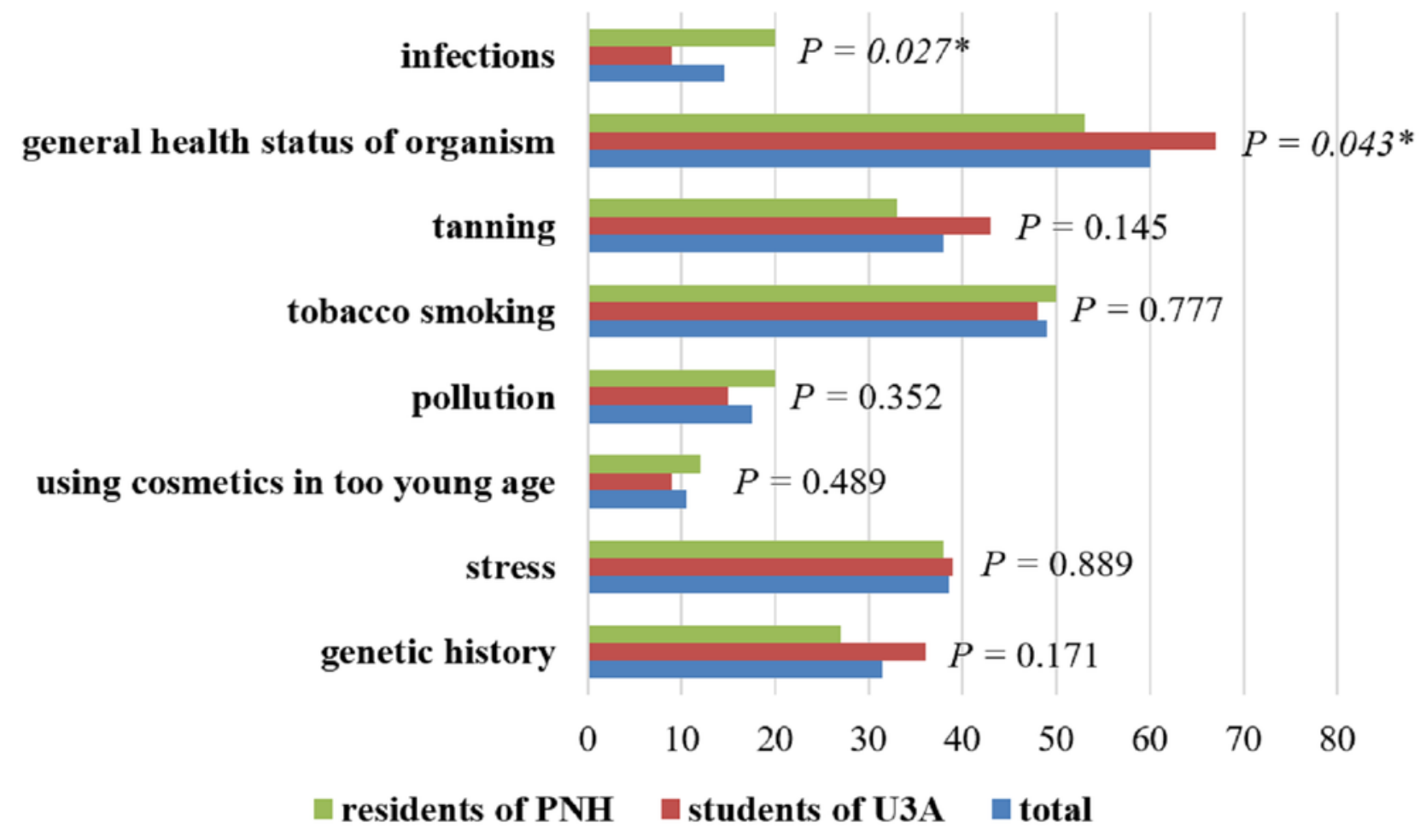


3

Typical stigma of ageing skin in the opinion of respondents

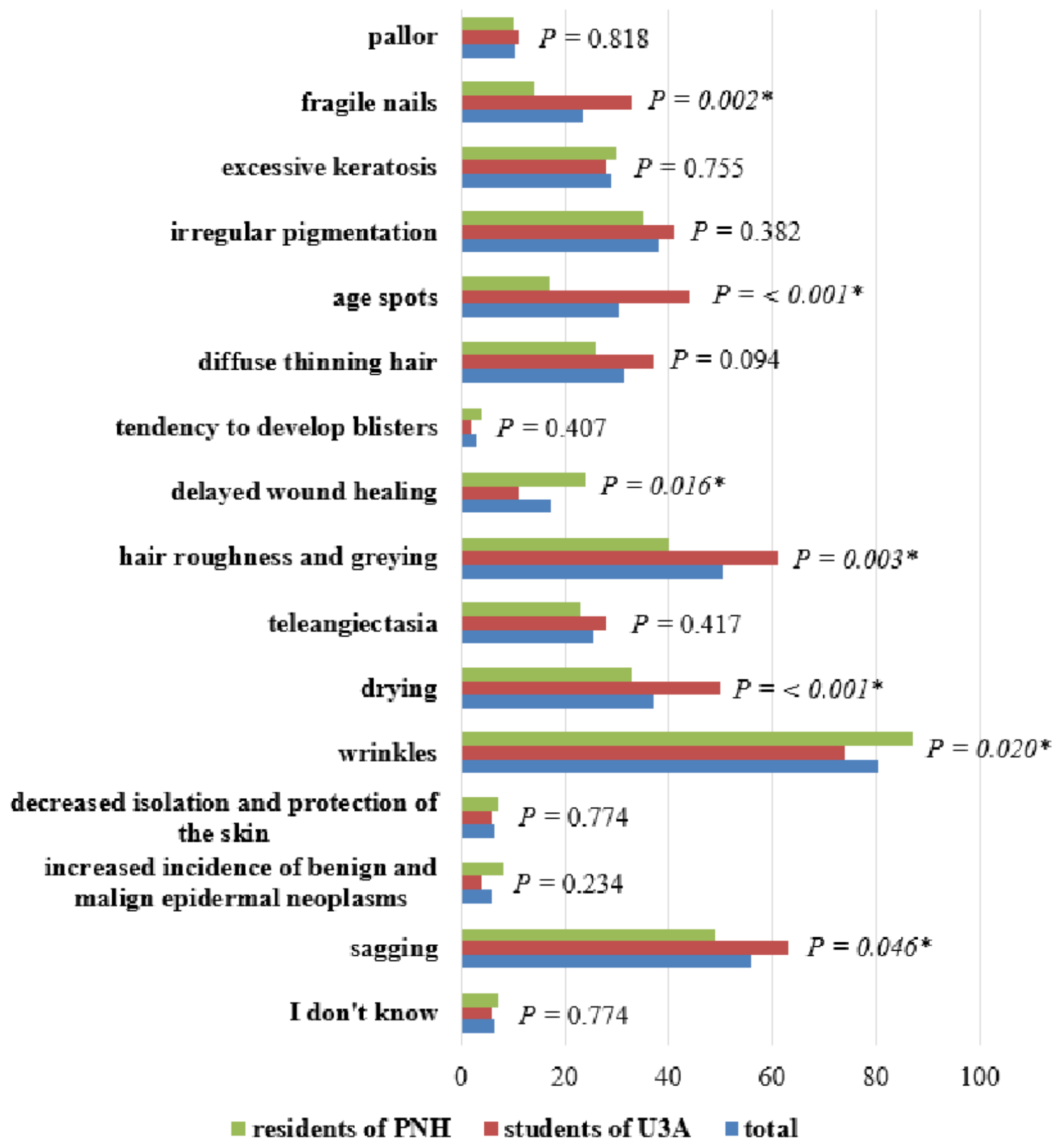


4

The most frequent skin problems in the elderly in the opinion of respondents

warts

vesicular diseases

fungal infections

xanthelasma

seborrheic dermatitis

neoplasms

drug reactions

bed sores

abrasions

leg ulcers

shingles

actinic keratoses

cutaneous horn

erysipelas

various types of eczema

itching

fibromas

stasis dermatitis

birth marks

I don't know
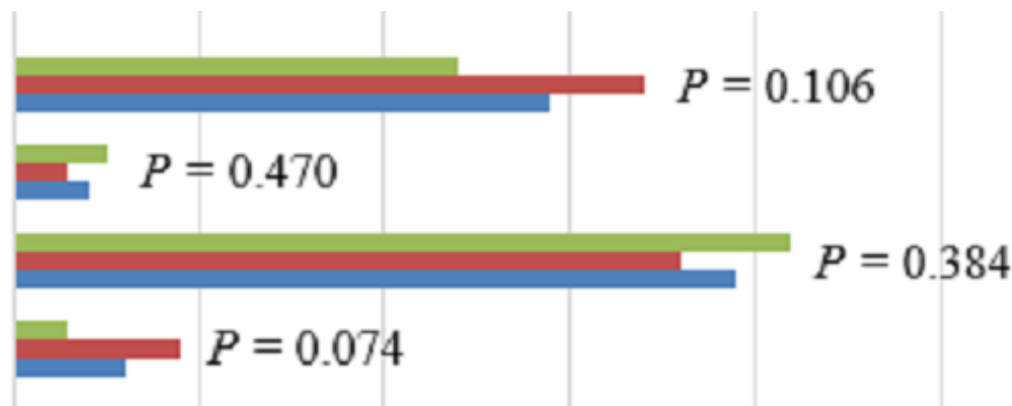

$P=0.228$

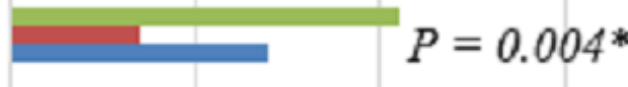

$P=0.194$

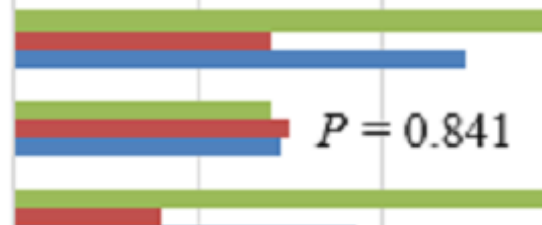

$P=0.001^{*}$

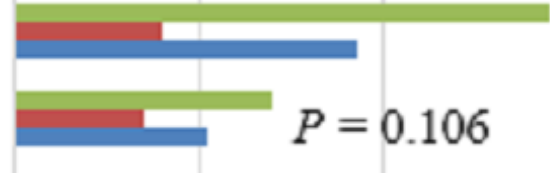

$P=<0.001 *$

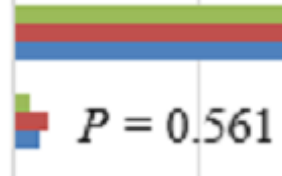

$$
\text { 드 } P=0.312
$$
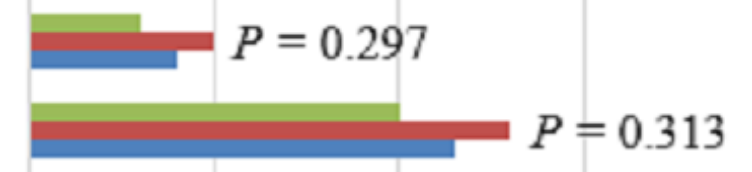

$P=0.044^{*}$

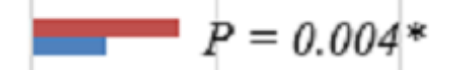

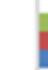
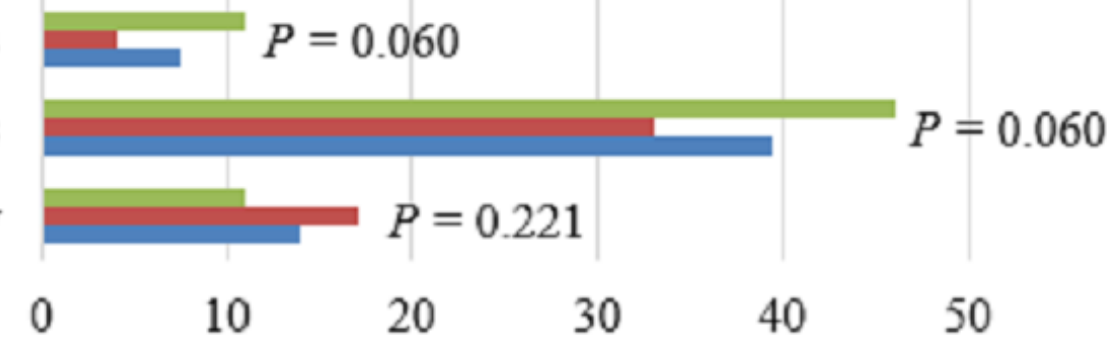

residents of PNH $\square$ students of $\mathrm{U} 3 \mathrm{~A} \square$ total 


\section{5}

Respondents' sources of information about skin diseases in seniors

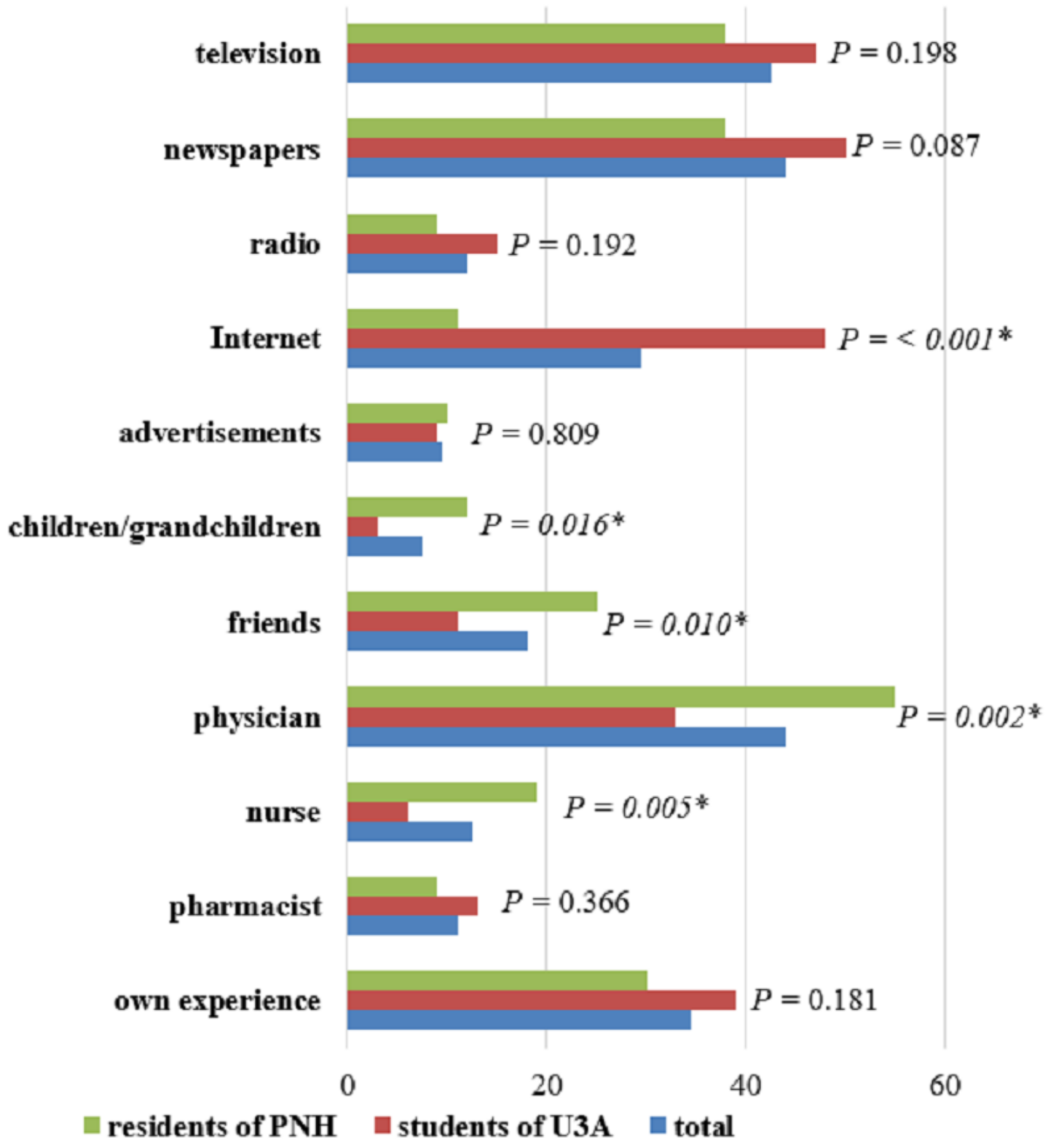

